\title{
Research into practice: Teaching notetaking to L2 students
}

\author{
Joseph Siegel \\ Stockholm University and Örebro University, Sweden \\ Corresponding author. Email: joseph.siegel@english.su.se
}

\begin{abstract}
This paper reviews and discusses research on notetaking during academic listening conducted in both first (L1) and second language (L2) contexts and is organized into two main categories: research that is beginning to impact English for academic purposes (EAP) classrooms and that which has yet to make an impact on EAP, but should. Overall, I assert that, while some relevant research on notetaking is reaching EAP classrooms, there is an abundance of knowledge from L1 contexts as well as a number of unexplored areas that have potential to improve instruction and student ability. Throughout the paper, I hypothesize why certain research findings are not being applied in classrooms. In concluding, I provide suggestions for how researchers and teachers might further support colleagues in applying research findings.
\end{abstract}

\section{Introduction}

The ability to take effective and efficient notes while listening to information is undoubtedly a crucial skill for students, whether they are learning in classrooms where their L1 or their L2 is being used as the medium of instruction. Notetaking has long been a stalwart competence in academic learning, particularly in tertiary education, where it has been described as THE distinguishing characteristic of higher education (van der Meer, 2012). Nearly one hundred years ago, Crawford (1925) conducted research on notetaking with L1 English users to empirically prove what many may consider to be common sense: that taking notes when listening helps to improve learning and retention of information. Since then, the positive impact of notetaking on performance has been reiterated both qualitatively (Badger, White, Sutherland, \& Haggis, 2001) and qualitatively (e.g., Kobayashi, 2006; Boran \& Yi, 2012), and the act of reviewing notes has also been emphasized (e.g., Bui, Myerson, \& Hale, 2013; Luo, Kiewra, Flanigan, \& Peteranetz, 2018). Thus, it goes without saying that notetaking is recognized as a component crucial to learning in academic contexts.

Despite its importance for institutional learning, the worldwide phenomenon of English medium instruction (EMI) (e.g., Dearden, 2014; Murata, 2018), and the corresponding increase in L2 English users participating in EMI, there has been relatively little research into various aspects of notetaking in an L2. In my view, this dearth of research often leaves L2 teachers and students grasping at straws, with teachers simply instructing students to 'take notes' heeding neither pedagogically or researched-based approaches to L2 notetaking development. Many teachers typically just do not know how to address this multi-faceted skill or how to make and justify pedagogic choices for notetaking (e.g., Siegel, 2018a). I base this claim, as well as the interpretations of research, on my experiences in teaching and teacher education for EAP classes in Japan and Sweden, and on presentations, seminars, and workshops on the topic in international forums, as well as my own research projects on academic listening and notetaking.

In general, many current teaching practices fail to acknowledge and address the complexity of L2 notetaking. One reason is a traditional focus on teaching individual language skills (e.g., a listening

\footnotetext{
(c) The Author(s) 2020. Published by Cambridge University Press. This is an Open Access article, distributed under the terms of the Creative Commons Attribution licence (https://creativecommons.org/licenses/by/4.0/), which permits unrestricted re-use, distribution, and reproduction in any medium, provided the original work is properly cited.
} 
course, a speaking assignment, a textbook focused on writing) as opposed to the integrative nature of notetaking (which involves listening, decision-making, writing/typing, reading, and possibly producing language in speech or writing based on notes). Scarcity of class time is another factor; notetaking may be considered as part of listening, and students simply listen and take notes with little to no time spent on the quality of the notes or on developing techniques to improve performance.

Despite being relatively overlooked from a research perspective in L2 contexts, notetaking research from L1 contexts has begun to explore the effectiveness of various organizational systems of notes (e.g., the outline, the Cornell method (Pauk \& Owens, 2014)) (e.g., Kiewra, Benton, Kim, Risch, \& Christensen, 1995), strategies for recording specific items of information, and distinctions between how taking notes (i.e., encoding) and using those notes (i.e., reviewing) impacts learning and performance. Ongoing developments in technology, such as laptop computers, eWriters, recording software, and slide-sharing platforms (e.g., Mueller \& Oppenheimer, 2014; Morehead, Dunlosky, \& Rawson, 2019), and the subsequent evolutions in notetaking preferences and habits have started to get attention in L1 but not L2 contexts.

We should ask why L1 notetaking maintains such a strong research interest and yet notetaking in L2 and EMI contexts has yet to enjoy the same attention. A general consensus (based on the vast number of EAP courses and textbooks as well as conference presentations and journal articles related to EAP) would suggest that notetaking in EAP needs to be taught; however, it is often approached in cursory ways. The impact on learning that comes from notes is at least, if not more, important in L2 contexts, as learners likely struggle with first-time comprehension, new terminology, rapid rate of speech, among other factors, compared to students studying in their L1s. The field of EAP should look to research completed in L1 contexts, determine the extent to which it is applicable to L2 notetaking, and integrate similar work for L2 academic learning and notetaking development.

In my view, the act of taking notes is in itself inherently more complex than many EAP teachers realize. It draws on a range of cognitive, linguistic, and physical abilities which must all operate in nearsimultaneous coordination. While listening, a notetaker must discern if what they are hearing is valuable and/or novel enough to record in notes. They likely choose a location for their notes (where on the paper, in which organizational format, if any, etc.). After deciding what to take notes on and where to do so, they need to pick a specific technique for recording each discrete item of information: verbatim or paraphrase? As an abbreviation or a picture? Next comes the actual writing, typing, or drawing. All this happens while listening out for the next item of information, a sequence that may be overwhelming for many L2 learners and one for which they look to their teachers for help. Teachers, in turn, can be challenged to cover this sequence in class, leading them to simply assume that saying 'take notes' and some encouragement is sufficient to stimulate notetaking development.

While my own personal experience and intuition lead me to surmise that L2 students may be struggling more than we recognize in EAP and EMI academic listening situations, survey results from a number of L2 contexts reveal notetaking to be an underestimated challenge. According to a large-scale survey in Japan ( $n=739$ ) (Crawford, Ducker, MacGregor, Kojima, \& Siegel, 2016), just over half of university students stated that they received notetaking instruction in high school English classes. In the Swedish context, nearly $90 \%$ of 187 high school students reported that they either had no notetaking instruction in L2 English or they were unsure if they had received such tuition (Siegel, 2019). Sixty-five percent of these students believe that their L2 English teachers can help improve their notetaking abilities, but only one third reported that teachers take any action to do so (Siegel, 2019). Further, many students on such surveys express a desire for more, and more explicit, attention to notetaking in their L2 English courses (e.g., Teng, 2011; Crawford et al., 2016; İpek, 2018; Kusumoto, 2019; Siegel, forthcoming).

Based on these findings, as well as personal insights, the need for attention to student notetaking abilities in L2 contexts is justified, not only for individual student development but also for EAP teacher education. As such, and partly because of the general dearth of studies on L2 notetaking, research from both L1 and L2 contexts has relevance for L2 language teaching and learning and for EAP and EMI in particular. For the purposes of discussion in this paper and for relevance to 
L2 notetaking, research summaries and commentary are divided into two main categories: (1) where I believe research is beginning to impact EAP classrooms and (2) where I feel that research is not currently impacting EAP classrooms but should be incorporated in the future. This paper reviews a selection of studies from these categories and organizes them in terms of those coming from L1 and L2 contexts, respectively.

\section{Research beginning to impact EAP classrooms}

Notetaking consists of two key functions: encoding and storage (DiVesta \& Gray, 1972). The encoding function relates to the actual taking of notes and is thought to focus listener attention on the incoming input, which in theory, helps them to learn and remember the information. I believe that in general, much of the emphasis that is currently placed on notetaking in EAP courses focuses on encoding; that is, students listen and take notes for the express purpose of demonstrating their ability to listen and record information. Teachers want to see that students have written something in their notes. Students encode information in order to show teachers they have listened and understood.

\subsection{Findings from $L 1$ research}

General findings from L1 research that are starting to be evident in EAP classrooms include the impact of formatting choice and the encoding options available to the notetaker.

\subsubsection{Overall format}

One important aspect of notetaking is the overall format that dictates or implies how notes are organized on the page. Kiewra et al. (1995) were among the first to investigate this aspect, and results of their study of undergraduate students $(n=54)$ showed that an instructed 'flexible' outline format leads to more idea units in notes than students' conventional formats or the matrix format. When it comes to EAP notetaking, Kiewra et al. (1995) and similar studies seem to have had some impact regarding to the attention given to notetaking formats. Teachers and commercial textbooks (e.g., Lecture Ready (Sarosy \& Sherak, 2013), published by Oxford University Press and Listening \& Notetaking Skills, (Lim \& Smalzer, 2014) Heinle-Cengage ELT series) often promote certain systems for notetaking (e.g., the outline format, the Cornell method). Pedagogic interventions for EAP notetaking (e.g., Hayati \& Jalilifar, 2009; Crawford, 2015; Siegel, 2016) have incorporated practice for specific formats over others as well. Song (2012) also demonstrated how certain formats (such as the outline) lead to the capture of hierarchical relationships of information in lectures more than a blank or uninstructed format and that note format can lead to differences in test performance among English as a second language (ESL) undergraduates. While various formats are evident in EAP classrooms and notetaking materials to some extent, a challenge remains related to teachers compelling students (with praise, attention, grades, etc.) to use a specific format regardless of the student's own individual preferences.

\subsubsection{The recording of single items}

The ways in which a single item of information can be recorded in notes varies: verbatim, paraphrase, abbreviation, image, or a combination thereof. Generative notetaking (i.e., not copying verbatim) is typically beneficial to processing, retention and learning of information, as the listener invests more cognitive energy than copying information in a word-for-word manner (Piolat, Olive, \& Kellogg, 2005). Findings from studies comparing laptop to longhand notetaking show that verbatim overlap is more common with laptop notetaking (e.g., Morehead, Dunlosky, \& Rawson, 2019), compared to generative forms of notetaking. Thus, taking notes longhand from a generative perspective, while being pragmatic and employing specific techniques at appropriate times, is likely an optimal formula. Paraphrasing, using abbreviations, and other generative techniques are commonly included in textbooks for L2 notetaking and demonstrated and encouraged by teachers. While practices that focus 
on these generative aspects of notetaking are valuable, I feel that EAP teachers often overlook opportunities to (a) compare different ways in which a single piece of information can be recorded, (b) make students explicitly aware of the options, and (c) stimulate meta-discussion about the various options and why one might choose a particular method over another, depending on the piece of information and/or the purpose for taking notes.

While the option of drawing pictures in notes may be valuable to save time and/or energy, the practice can also help in L1 notetakers' retention of target information (Wammes, Meade, \& Fernandes, 2016). The authors theorize that a strong link between elaborating on physical characteristics of an item, using visual imagery, and activating motor skills creates a powerful 'memory cue for later recall' (Wammes et al., 2016, p. 1755). In their research with L1 English undergraduate students $(n=30)$, words from an 80-item list that were drawn in notes were better recalled than those that were written.

However, much notetaking in EAP courses focuses for the most part on the written word (in various forms) as the key vehicle for recording information. While symbols such as \#, =, @ can be useful, I do not view them as containing much semantic information. Instead, they emphasize relationships between two or more ideas rather than the ideas themselves. The notion of visual signals and symbols in notes is typically included in L2 notetaking textbooks but is often restricted to items such as $>$ to mean 'greater than' or an arrow pointing up to mean 'increase' (e.g., Lecture Ready (Sarosy \& Sherak, 2013), published by Oxford University Press and Listening \& Notetaking Skills (Lim \& Smalzer, 2014), Heinle-Cengage ELT series). If one agrees that the most important words that should be recorded in notes are content words (i.e., primarily nouns and verbs, not grammatical or function words), such symbols or images are often of little value. Textbooks and teachers may see teaching such symbols as notetaking, but my perspective is that overemphasizing such practice merely masquerades as notetaking at the expense of decision-making and recording of main lecture content.

\subsubsection{Reviewing notes}

In terms of review of notes, participants in Kiewra et al. (1995) also performed one of two different review tasks: a standard review practice of re-reading notes or writing a summary essay about a lecture. Results showed that the standard form of review generated better scores on a test of lecture content. Studies such as Kiewra et al. (1995) and surveys and summaries of previous studies (e.g., Dunkel, 1988a) demonstrate that review of notes is worthwhile. This fact supports the priority given to notetaking in EAP; in other words, that notetaking generates a record of information to review, which in turn leads to more opportunities to review and a higher chance that information will be retained. Few could argue with the logic that writing down information and then reading through it later is a good idea for learning. Dunkel, Mishra, and Berliner (1989) found that notetaking without review may not facilitate learning and retention of lecture content regardless of whether a notetaker is operating in their L1 or L2. As such, supporting EAP students in their taking and use of notes is worthwhile endeavour and justifiable uses of class time. However, from speaking with teachers in the field of EAP and reflecting on my limited experience, most emphasis in L2 notetaking remains at the encoding stage and focus on the storage element remains underdeveloped. Teachers may encourage students to 'study notes' after class, but systematic guidance in how to use those notes is an area for future development.

\subsection{Findings from $L 2$ research}

I believe a small but promising amount of relevant research, specifically that focusing on encoding, systemized instructional methods, and the trialling of different formats, is making its way to EAP classrooms. The discussion draws on an international collection of research, signalling that EAP notetaking is a global area of interest.

\subsubsection{Differences between L1 and L2 notetakers}

In a relatively early and much-needed area of L2 notetaking research, a group of studies focused on exploring and documenting the differences between L1 and L2 English students taking notes while 
listening to the same English lectures. Not surprisingly, many of the findings reinforce logical expectations: that L1 English students recorded more and higher-quality notes than their L2 English counterparts. As with Crawford's (1925) study that showed notetaking improves test scores, most work on the differences between L1 and L2 notetakers establishes empirically what many might assume: that notetaking is easier when students listen and takes notes in their L1 than their L2. Clerehan (1995) compared the notetaking quality of students on a commercial law course $(n=200)$ and found major defects among the L2 group in recording major headings, supporting details and specific examples when compared to the L1 group. However, several similarities were also identified; specifically, that both groups made use of strategies such as indenting, underlying, and bullet points.

Dunkel (1988a) also compared the notes of groups of L1 and L2 English students to better understand the quality of the notes and how effective they might be for answering test questions. Findings suggest that regardless of whether notes are taken in the L1 or L2, aiming for conciseness and efficiency in notetaking is preferable to a strategy of simply writing as much as possible. This emphasis on conciseness and brevity while still maintaining denotative meaning provided a clear goal for EAP teachers and students. On average, the L1 group scored higher than their L2 counterparts on both concept and detail when questioned about a lecture. A year later, Dunkel et al. (1989) compared L1 and L2 groups ( $n=136$ and $n=123$, respectively) with the aim of better understanding how working memory and L1 or L2 can affect notetaking. The L1 group scored significantly better when it came to recognizing main lecture concepts and more detailed information, evidence that further underscored the challenges L2 English users face when trying to learn from lectures, along with the need for explicit support for L2 notetaking.

In a study involving L1 English $(n=10)$ and L1 Spanish $(n=12)$ users learning French as an L2, Barbier, Roussey, Piolat, and Olive (2006) examined how notetaking in the L1 or L2 may differ in terms of perceived difficulty of notetaking, the volume of notes, how closely they matched the content of the source text, and use of abbreviations. Comparisons of notes taken in the participants' L1s and L2 French showed no significant differences in regard to structural features (e.g., lists, bullet points), suggesting that students employ notetaking similarly in both languages, assuming a minimum threshold proficiency. Analysis of notes showed more words written in the L1 versions, and students abbreviated more words in their L1 than in L2 French. Based on these findings, L2 students may benefit from explicit practice in paraphrasing and abbreviating information in notes, activities which are sometimes included in L2 notetaking instruction.

These studies are significant in establishing and documenting the challenges of notetaking in an L2, while at the same time demonstrating a type of transferability of certain techniques from L1 to L2 notetaking. These initial studies provided a basis from which research and teaching could improve. They identified the stress faced by L2 notetakers and signalled the need for improvement.

\subsubsection{Notetaking in L2 classrooms}

General advice for teaching notetaking to L2 students was expressed in Dunkel's (1988b) article that reviewed L1 research on notetaking at that time and presented a set of axioms of good notetaking that could be adopted in the L2 classroom. Among the principles Dunkel (1988b) presented for teachers were demonstrating various notetaking formats, teaching students to recognize verbal signposts in lectures, encouraging students to take notes, and examining and providing feedback on notes. These practices have largely become commonplace in EAP courses that include academic listening and notetaking. Dunkel's advice for students (based on a summary of 38 study manuals) includes inventing and using abbreviations, being selective about what gets included in notes, and recording key words. Again, these are topics we often find in notetaking materials.

A more recent overview of relevant research in both L1 and L 2 contexts was provided by Crawford (2016), which aimed to better inform the L2 teaching community. Among the points the author makes are emphasizing the need for teachers to support students' notetaking ability (rather than leaving them to their own devices), employing a variety of techniques (e.g., abbreviation, underscoring, and highlighting) to increase the effectiveness of notes, and encouraging teachers (and their students) to 
focus on recording content words (as opposed to grammatical, or function, words). This summary article also served to raise teacher awareness of issues relevant to notetaking, such as working memory capacity and the potential effects of notetaking options (e.g., traditional longhand or digital) can have on performance and memory. Like those summarized by Dunkel (1988b) nearly three decades ago, I believe that many of these techniques have made their way into EAP classrooms, either through commercially produced materials or by increasing teacher awareness of the many steps involved in and factors that impact notetaking, although I am sceptical that memory capacity and technology are incorporated to any meaningful extent.

Whereas I believe that advice such as that presented in Dunkel (1988b) is largely accepted as contributing to EAP notetaking instruction, other classroom practices that align with research are also taking hold. Drawing on interactive potential and socio-cultural approaches to language learning, Lowen and Metzger (2019) introduced a series of activities for 'active notetaking'. For example, students exchange notes with classmates and are prompted to find and circle specific information in their partner's notes or to make a brief presentation to peers based on the notes they have taken. This classroom practice aligns with research from Luo et al. (2018), who showed the benefits of revising, reviewing, and collaborating with partners and promotes a more student-centred means of learning from notes.

Another activity promoted by Lowen and Metzger (2019) involves students taking notes from various combinations of information delivery systems (with audio only; with visual aids only; or with audio and visual aids). This exercise recognizes the value of multimodality and multimodal competence on the part of the lecturer (e.g., Morell, 2018) and the impact myriad factors can have on notetaking performance. Teachers are becoming more aware of how multimodality can support or hinder notetaking, particularly in L2 contexts. Flowerdew and Miller (1997) highlight the potential for cognitive overload when students are presented with too much information in multiple forms while trying to take notes. This view is supported by cognitive load theory in relation to notetaking (Jansen, Lakens, \& Ijsselsteijn, 2017). Cognitive load theory states that if more information is present than one's cognitive resources can handle, performance will suffer. As Jansen et al. (2017) observe, notetakers are already splitting their attention between listening to and recording information. The addition of visual aids and multiple sources of aural input likely confound notetaking, at least for some students. Still, since this multimodal experience closely replicates what happens in real EMI lectures, in my view, it is justifiable for EAP to mimic EMI closely, at least occasionally, so students can train their skills in more authentic (albeit simulated) situations.

\subsubsection{Overall format and intervention studies}

In a study involving 257 undergraduate ESL students, Song (2012) examined student notes in terms of different levels of hierarchical information determined by lecturer patterns. Not surprisingly, results showed that the number of topical units in notes and the organization of those notes were good indicators of the notetaker's L2 listening proficiency level. The study also examined notes taken in a blank format compared to an outline format. Students who used the outline format performed slightly better on open-ended questions than those who used the blank format. This study relates to Kiewra et al. (1995) from the L1 context in that it focuses on how notetaking format can affect student capacity for recording information from lectures. Various textbooks present and promote different formats. Likewise, teachers may encourage students to adopt certain formats based on their own preference. Even the text type or lecture content can influence formatting choices, as Bui and Myerson (2014) point out in their research comparing the outline format and illustrative diagrams.

When it comes to notetaking instruction, L2 intervention studies often promote entire notetaking systems, such as the Cornell method, which involves organizing note paper with a section for jotting notes during the lecture and a separate column where main ideas and relevant questions are written, with space for a summary at the bottom of the note page (see Pauk \& Owens, 2014, for a comprehensive overview of the Cornell method). Hayati and Jalilifar (2009), for example, found that L2 English students in Iran $(n=60)$ trained in the Cornell method performed better on comprehension tests than did uninstructed notetakers. Crawford's (2015) study of Japanese L2 English students $(n=21)$ also 
included a component focused on the Cornell method, along with explicit instruction for a range of techniques, including recording content words, using abbreviations, and highlighting. In Taiwan, Tsai and $\mathrm{Wu}(2010)(n=108)$ also incorporated Cornell method training and found that instruction had a significant impact on performance regardless of whether notes were taken in L1 Chinese or L2 English.

Other intervention studies have taken place in EAP classrooms that have opted for alternative formats to the Cornell method. Siegel (2016) conducted an intervention study with university EAP students in Japan $(n=87)$ that focused on utilizing skeleton notes in the outline format. Over the course of a six-week instructional period, students listened to short, semi-authentic lectures created by the author. Students received skeleton notes for each lecture, the content and volume of which were gradually reduced over the course of the intervention. The instruction consisted of guided practice for deciding what information to record in notes and when to do so during the lectures (e.g., when the speaker pauses or goes off on a tangent). Results from pre- and post-intervention notes showed significant increases in the number of information units included in notes as well as a $60 \%$ increase in the number of students adopting the outline format.

\subsubsection{Moving on from format: Effects of classroom interventions}

As time goes on, I have become less convinced that format has a strong influence on note quality (this, despite promoting the outline format in my 2016 project). Yes, some structure to notes is beneficial, and having a pre-determined plan and structure for notetaking is advisable; however, the primacy of recording individual items has garnered more of my support than overall format. In an effort to make interventions less dependent on any single prescribed format or system, and to acknowledge the wide range of individual preferences for notetaking, more recent interventions (e.g., Siegel, 2018b; Kusumoto, 2019) have sought to provide flexible instruction and support that can be incorporated in any notetaking format. A four-step procedure for notetaking instruction including decision-making, verbatim, and paraphrasing stages, used in conjunction with authentic materials (i.e., TED Talks), was introduced in EAP courses for upper-intermediate proficiency students at Swedish upper secondary (i.e., high) schools (Siegel, 2018b $(n=44)$; Siegel, $2019(n=187))$. While slight increases in performance on post-listening tests were evident, results from notetaking samples in Siegel (2018b) showed a statistically significant increase in the amount and quality of information in notes following the intervention (as measured by 'information units', which are elaborated upon later in the Section 'Evaluating note quality').

Siegel's (2019) report provided useful background information that a majority of students in the Swedish context had not received explicit notetaking training in their L2 English courses prior to the intervention. Participating teachers $(n=4)$ expressed their desire for training in explicit techniques for notetaking, with several stating that they did not feel they actually taught notetaking and often assumed their students had developed notetaking abilities via their other courses. The intervention included the four stages outlined in Siegel (2018b). Findings from a post-intervention survey indicated that the stages focused on taking notes verbatim and working to simplify and paraphrase information were the most enjoyable and effective for improving students' notetaking ability. In addition, after putting the stages into practice in their own classrooms, teachers responded positively, with one stating that '[this approach made it] so visible for them to see their own progress' and another stating that 'I could see progress [in their choices based on] their awareness of what happens when you listen and you have to determine what's useful or not' (Siegel, 2019, p. 93).

Kusumoto (2019) replicated Siegel's (2018b) study with one major modification: the proficiency level of the participants $(n=59)$. Whereas students in Siegel $(2018 \mathrm{~b})$ were at an upper-intermediate level (approximately B1-B2 on the Common Europe an Framework of Reference for Languages scale), those in Kusumoto (2019) could be classified as high beginners (approximately A2). Using the same intervention stages, TED Talk materials, and data collection procedures as Siegel (2018b), Kusumoto's (2019) students showed slight, non-statistically significant increases in information units on note samples from pre- to post-intervention. As the author points out, the results were likely affected by the level of the lecture listening materials, which were arguably too advanced for the 
students. Despite the absence of significant gains, post-intervention survey results showed that up to $90 \%$ of students agreed that certain stages, particularly verbatim recording of notes and simplification, helped their notetaking ability, findings similar to Siegel (2019).

One major caveat of many intervention studies set in EAP classrooms, including those summarized earlier, is a lack of control groups. As such, claims made about the effectiveness of the interventions can be called into question as being only better than 'nothing at all'. To address this gap, Sakurai (2018) compared the effects of notetaking instruction on a group of Japanese L2 university students $(n=56)$ who were divided into an intervention and a control group, respectively. Half of the group underwent a 15-week programme that included academic listening and notetaking instruction, the latter of which included a range of techniques (e.g., use of headings, colour-coding, and abbreviations) along with a variety of organizational formats (e.g., 'linear outline notes, charts and diagrams') (Sakurai, 2018, p. 1025). Pre- and post-intervention listening comprehension test results showed minor gains for the note group compared to the control group. More notable gains were made by the note group in terms of the number of English words, abbreviations, and symbols in notes.

These findings are similar to that of Siegel (2018b) in Sweden, where the intervention's effects were much more on evident evaluations of note content rather than comprehension tests. The inability of such studies to demonstrate significant gains on post-listening comprehension tests can be explained through several factors: for example, notes may have been of a certain quality but their content may not have matched the test questions; students and the test maker may have had different priorities when listening to the source material; and/or the quality of the test items themselves may vary. For these reasons, I view notes themselves as more valuable than test scores.

In another quasi-experimental design for notetaking instruction (Siegel, 2020b) intermediate and advanced level EAP students in Sweden were divided into control and intervention groups. Following a ten-week programme of instruction, both intervention groups showed statistically significant gains in the volume and quality of their notes in comparison to the two control groups, although the intermediate control group also improved significantly. Based on these results, I tentatively suggest that explicit notetaking instruction can benefit both intermediate and advanced level students, with the greatest benefits being exhibited by the advanced learners.

Studies like those presented in this subsection indicate that some research is actively influencing and taking place within EAP classrooms, though these contexts have been somewhat limited in the research undertaken. They further validate that, while initial steps are in progress, teacher competence in notetaking instruction continues to be an area in need of attention.

\subsubsection{Summary: Research beginning to impact notetaking in EAP classrooms}

As demonstrated by the summaries and discussion in Sections 2.2.3 and 2.2.4, several aspects of notetaking research in L2 contexts are beginning to impact classroom practices. These are small steps necessary to address teacher and student needs. While teachers and researchers are expending some effort to explore research-based options for teaching L2 notetaking, a number of issues, particularly in relation to the intervention studies, need to be addressed. For many of the studies summarized, important variations exist that can make comparisons, and therefore conclusions, difficult. Time of instruction, materials used, and specific content of the interventions all vary between studies, and thus, while it is clear some research is having an impact on and being generated within L2 contexts, more consistency in research design is needed to solidify findings and justify pedagogic recommendations. Lack of replication remains a concern as well. Additionally, to be of more practical use in EAP classrooms, concrete descriptions and examples of the instruction included in intervention studies would be welcome.

This section has demonstrated that at least some notetaking research is making its way into EAP classrooms. To speculate, I expect that a main reason for this is general dissatisfaction on the part of teachers with how notetaking has been dealt with in the past. It is a crucial skill that only becomes more complex when working in an L2. Teacher education programmes and pedagogic literature do not cover notetaking to any great extent, leaving teachers to depend only on their instincts, without 
sufficient support or guidance from other sources. Some teachers recognize the need for improvement and have started to take action, although as illustrated in Section 3, several potentially beneficial research avenues have yet to be realized in EAP classrooms.

\section{Research that has yet to impact EAP classrooms but should}

Research on notetaking is a small but expanding field. The body of L1 notetaking research has been rapidly widening, exploring individual differences among notetakers and what students do with notes after they are taken. L1 research also includes multiple studies targeting the use of technology and how it has impacted notetaking. Along with these advancements, it is important to monitor and understand student habits and preferences. Findings from L1 notetaking research have strong potential to positively inform and affect L2 classrooms; however, it is my view that disappointingly little L1 research has yet to make significant impact on L2 notetaking instruction.

I can only speculate on why more research on notetaking does not reach the classroom: some teachers may be reluctant to move beyond a traditional view of notetaking that merely involves orders ('take notes') and encouragement, taking a somewhat apathetic stance that the status quo is 'good enough'; those teachers who are interested in adopting new practices already do so (as evidenced by the intervention studies in Section 2.2.4), but others are unconvinced; despite its generally agreedupon importance, notetaking fails to receive an appropriate allocation of class time; and/or a possible belief that each student has an individual responsibility to develop notetaking on their own with little to no explicit, scaffolded action taken by the teacher. In spite of these arguments, I see several aspects that remain in need of attention, and there are a number of important findings and themes from research that have yet to be applied in L2 classrooms.

\subsection{Findings from 11 research}

\subsubsection{Habits and preferences}

In a large-scale survey of university students, Morehead, Dunlosky, Rawson, Blasiman, and Hollis (2019) aimed to understand habits and preferences related to notetaking used in current practice, an essential venture given the rapidly changing ways teachers present information in lectures and the ways in which students interact with and learn that content. Unsurprisingly, more than $95 \%$ of the more than 500 participants reported taking notes and more than $85 \%$ feel taking notes is useful (Morehead, Dunlosky, Rawson, Blasiman, \& Hollis, 2019, p. 6). A majority of students (86\%) reported preferring writing notes longhand in a notebook, although nearly half stated that they use laptop computers at least sometimes to take notes.

General surveys of L2 notetaking practices and preferences like Morehead, et al. (2019) would help inform EAP and EMI teachers of how best to support and develop students' notetaking abilities and needs. Such research would provide insights into questions related to how and why students take notes, the content of those notes, and the ways in which students use notes after the initial recording. All of this information would help L2 educators plan for how to support and extend students' preferences as opposed to strictly dictating a particular method or format that students MUST use.

\subsubsection{Individual factors}

A wide array of individual differences in notetaking ability and related skills can impact individual development. Factors such as handwriting speed, working memory, and motivation were investigated by Reddington, Peverly, and Block (2015) to determine any differences between genders. They found that females recorded significantly more information in notes and did better on written measures of recall than their male counterparts. The relationship between working memory and lecture notetaking was further explored by Bui and Myerson (2014). In my view, consideration of individual factors like gender or variations in working memory are informed by class observations, discussions with practising teachers, and reviews of notetaking materials, are rarely acknowledged in L2 EAP teaching. Instead, 
individual learner factors related to notetaking seldom affect teaching, and notetaking in EAP is often viewed as a 'one size fits all' despite that view being unsupported by research.

Probable reasons for overlooking individual preferences include, in my opinion, a general lack of pedagogic knowledge on notetaking on the part of some EAP teachers. This, coupled with lack of confidence about how to approach notetaking, would imply that teachers may not be able to identify, diagnose and plan instruction themes relating specifically to individual needs. While many teachers are skilled in doing this for other language skills (e.g., choosing reading materials and lessons for low, intermediate, and advanced level students; targeting grammar instruction at realistic proficiency levels), notetaking seems to be graded according to a 'good or bad notetaker' distinction, with little room for individual subtlety. Another possible reason relates to the combination of skills involved in notetaking (listening, deciding, writing), and a teacher's challenge to identify which particular skill may be the root of the issue or whether it is a combination thereof. Further explanations may be linked to lack of planning and class time and to variations in student background knowledge and motivation. All told, accounting for a plethora of individual notetaking capabilities in a single classroom would be an immense task, but one that the field should start to grapple with.

\subsubsection{Systematic review of notes}

Whereas much research in L2 notetaking has focused on the encoding function and the use of notes on post-listening comprehension tests, L1 research has also paid significant attention to the storage function and to review of notes. For example, findings from Luo et al. (2018) indicated that students taking notes longhand benefit more from the storage function (i.e., reviewing their notes) than they do from the encoding function; in contrast, laptop notetakers benefited more from the process. The value of the storage function has been shown by several previous studies, which support a common sense notion that reviewing notes leads to better learning than taking notes but not reviewing them (e.g., DiVesta \& Gray, 1972; Dunkel et al., 1989; Kobayashi, 2006; Luo, Kiewra, \& Samuelson, 2016; Luo et al., 2018).

It seems obvious to me that explicit focus on structured and systematic reviewing be incorporated into instruction, yet developing familiarity with various ways engagement with notes can take place (e.g., quizzing oneself, recopying, adding to, and/or restructuring notes) rarely occurs in EAP classrooms, in my experience. Instead, EAP classes tend to focus on immediate display of notes and immediate testing rather than delayed use and stimulation of recall. This makes short-term memory capacity a constant potential interfering factor. Review and use of notes is another area where assumptions are made about notes but where more overt awareness and instruction would be welcome. Attention to these types of academic skills could help boost the usefulness of the notes students in those classes take and could also transfer to EMI contexts.

\subsubsection{Technology and notetaking}

Another major area where L1 research has blossomed in contrast to L2 involves the rapid developments in technology and the impacts those can have on notetaking. EAP courses and textbooks for notetaking typically focus on 'traditional' notetaking that involves taking notes longhand with a pen and paper. L1 contexts, however, have begun exploring how longhand and laptop notetaking differ and the extent to which notetaking method can impact learning and retention (e.g., Mueller \& Oppenheimer, 2014; Luo et al., 2018). While Mueller and Oppenheimer's (2014) initial study indicated that longhand may be preferable to laptop notetaking in terms of test performance, a replication by Morehead et al. (2019) failed to confirm the original findings; therefore, as Morehead et al. (2019) observe, 'evidence does not provide a definitive answer as to [which notetaking method leads to better learning]' (p. 773). I applaud L1 researchers for asking these questions, which have thus far not attracted attention in the L2 field in terms of notetaking, at least to my knowledge. In addition to incorporating laptop notetaking in research design, Morehead et al. (2019) included eWriters in their study and concluded that taking notes with an eWriter resulted in similar quality and quantity as longhand notes. Apart from Debopriyo, Brine, and Murasawa (2014), who investigated the use of 
five notetaking applications (apps) in L2 classrooms, digital notetaking has not yet been explored in L2 notetaking.

\subsection{Findings from $L 2$ research}

Various aspects of notetaking and related instruction have been explored from an L2 research perspective, but much of this work seems to have had little impact on teaching and learning. While several intervention studies have taken the initiative to explore how L2 notetaking instruction and performance might be improved, a number of topics that have been introduced to the field have yet to take hold. Again, reasons for this may include lack of teacher interest or motivation, a preference for maintaining the status quo, and/or a feeling that each teacher knows and is responsible for their unique teaching situation, and thus widespread adoption of general practices for notetaking are irrelevant or unnecessary. That said, I feel that areas such as materials analysis and choice, technology for L2 notetaking, translanguaging in notes, and assessment of notes concern most if not all EAP teachers at one time or another.

\subsubsection{Materials analysis}

Many EAP classes utilize commercially published notetaking textbooks (e.g., the Lecture Ready (Sarosy \& Sherak, 2013) series published by Oxford University Press). These days, materials are evaluated and scrutinized in systematic ways in order to help teachers and administrators make objective and sound decisions about textbooks. Several decades ago, Hamp-Lyons (1983) conducted a survey of eight notetaking textbooks and included and included the following criteria: the course should teach (not only practice) notetaking skills and techniques and should include model notes in several alternative styles. However, since that time, specific criteria for the evaluation of L2 notetaking textbooks have not been systematically developed in the same way as materials analysis for materials targeting other language skills (e.g., Sheldon, 1988; Tomlinson, 2010; McGrath, 2016). I wonder why evaluation criteria specifically for teaching and learning notetaking in an L2, such as approximation of the lecture genre, notetaking-specific goals, a range of systems and techniques for notetaking, and accounting for both the encoding and storage functions of notes, have yet to be developed and applied systematically.

\subsubsection{Technology and notetaking}

Research related to digital notetaking has yet to impact L2 English classrooms, where the traditional longhand method remains more popular. Even notetaking textbooks like those mentioned earlier lack any mention of or support for L2 notetaking via technology. Debopriyo et al. (2014) found that apps such as Evernote and Springpad generated positive student reactions and task performance. These favourable perspectives with potentially positive results for laptop and eWriter notetaking from L1 contexts, leads to an unrealized expectation that digital notetaking would enter the L2 classroom. As time passes, it is likely this area will continue to expand in EAP contexts. One wonders if digital obstacles (unfamiliarity with the technology, lack of flexibility compared to pen and paper notetaking, etc.) might only amplify the stress and struggle among students taking notes in their L2. This issue begs the question: if digital options are meant to make notetaking easier for L1 students, wouldn't the same logic also apply for the L2?

\subsubsection{Translanguaging in notes}

When it comes to language choice, it seems as if there is a traditional view that in an L2 class, the L2 should be used at all times. In other words, code switching and translanguaging in notes in EAP classrooms may be frowned upon by teachers who wish to have evidence of their students' listening comprehension and notetaking ability IN THE L2. However, as I have argued previously (Siegel, 2020a), I believe that more flexibility should be accepted in notes and that translanguaging in student notes should be recognized and appreciated as a strategy that allows students to accomplish the task for 
representing ideas in notes in ways that are most effective and efficient for THEM. While I recognize the need for EAP teachers to evaluate notetaking ability and thus for them to promote L2 usage, when students move on to EMI courses, language choice becomes less of an issue since EMI is focused less on language use and more on content learning. Tsai and $\mathrm{Wu}$ (2010) investigated whether language use (either L1 Chinese or L2 English) affects the quality of notes taken by Taiwanese university students $(n=104)$ when listening to L2 English. They found that students taking notes in the same language as the one they were listening to performed better on post-listening comprehension tests. The authors also concluded that taking notes in Chinese was less effective than taking notes in English when the goal is 'to capture information delivered in English' (Tsai \& Wu, 2010, p. 120). Despite this claim, I believe that the L1 might be more efficient when recording certain information, particularly if the student comprehends correctly but does not know how to spell the information accurately in English (e.g., Siegel, 2020a; forthcoming).

Reluctance to embrace (or even promote) translanguaging in notes may be related to a perceived need for strict teacher control, the need to evaluate note quality (see Section 3.2.4), and the fact that the teacher may not share a student's L1 and thus be unaware of what the student has recorded. The teacher in such cases would be unable to confirm if the student is on task and unsure of how to support the student. In terms of supporting students to use all available linguistic resources and strategies, encouraging (or at least not actively deterring) translanguaging in notes can be worthwhile.

\subsubsection{Evaluating note quality}

Among teachers who evaluate note quality, either for formal grading purposes or informally as classroom practice, a range of options is often employed. Teachers might comment on the total number of words, appearance and organization of information on the page, the quality and clarity of the handwriting, and so on. These criteria may be applied idiosyncratically by the teacher or depending on the student. However, in order to present an arguably more objective approach to note quality, one that reflects novel information presented in a given speech sample and the amount of notetaking while listening to that speech, the notion of the 'information unit' (IU) has been proposed (Siegel, 2018c). An IU has been defined as: 'the smallest unit of knowledge that can stand as a separate assertion ... the smallest unit one can judge as true or false' (Anderson, 2014, p. 104). IUs typically 'contain a combination of at least two words, abbreviations, pictures, and/or symbols, which may include an agent or actor (noun), an action (a verb), and/or a description (an adjective or adverb), the combination of which creates a complete proposition that is explicit and relies more on the written notes themselves rather than on memory to stimulate recall' (Siegel, 2018c, p. 87).

Siegel (2018c) goes on to demonstrate, through analysis of note samples, how the IU method for note quality compares to other measurements such as total words, total number of notations, and content words, all of which may neglect to capture complete and meaning ideas presented by a speaker. Instead, the writing of random and potentially unconnected words could jeopardize the ability to stimulate recall of complete ideas at a later date. The IU concept encourages teachers to look for and credit complete ideas evident in notes and for students to aim to record in the same way.

The concept remains a work in progress. Siegel, Crawford, Ducker, Madarbakus-Ring, and Lawson (2020) investigated the extent to which teachers agree on what language samples constitute IUs in a given speech, a study that revealed the complexity of applying the IU among several teacherresearchers. As the authors observe, while the IU is preferable to and theoretically a more meaningful measure than total words, more work at the theoretical and practical levels are needed to put it into widespread practice. Although there are indeed drawbacks and caveats, IUs present one option for improving and standardizing how notes are evaluated in EAP. At this point, teachers may be reluctant to adopt such a concept, as it is time-consuming to identify and tally IUs, although the IU could feed back into notetaking instruction (i.e., a particular IU can be recorded in several different formulations). 


\section{Conclusion}

As stated at the beginning of this article, the need for and importance of L2 notetaking has increased in response to the rapidly expanding EMI phenomenon on a global scale. In response, a small number of teacher-researchers have taken action to implement improvements and incorporate selected findings from both L1 and L2 notetaking research into their pedagogy. However, there are still a number of challenges that need to be overcome before more research on notetaking makes its way consistently and continually to EAP classrooms. These include a neglected view from a teacher education perspective, a complex combination of skills involved in notetaking, along with wide ranging individual habits and views on how notes should be taken. Comfort in maintaining the status quo of telling students to 'take notes' and assuming they can do so effectively is a further obstacle. Yet despite these issues, most L2 secondary and tertiary students and instructors would likely agree that the ability to listen to, take notes during, and learn from L2 academic speech are crucial for success in EMI.

In order for more research to reach the classroom, academics may need to take special care in providing clear and unambiguous recommendations and pedagogic implications stemming from their studies. Providing explicit examples of activities and justifications for those activities, along with step-by-step procedures would likely support teachers in applying research findings without the additional and sometimes confusing stages of transferring scientific information at the theoretical and/or descriptive levels into classroom practice. Research has the potential to furnish teachers with new ways of approaching their craft and stimulating experimentation in the classroom (e.g., Larsen-Freeman, 2015). While there will likely never be universal agreement on one best method, system or technique for notetaking, it is essential for teachers to be aware of the multitude of issues that affect notetaking performance and instruction.

\section{References}

Anderson, J. (2014). Cognitive psychology and its implications (8th ed.). New York, NY: Worth.

Badger, R., White, G., Sutherland, P., \& Haggis, T. (2001). Note perfect: An investigation of how students view taking notes in lectures. System, 29, 405-417.

Barbier, M.-L., Roussey, J.-Y., Piolat, A., \& Olive, T. (2006). Note-taking in second language: Language procedures and selfevaluation of the difficulties. Current Psychology Letters, 20(3), 1-14.

Boran, L., \& Yi, H. (2012). The effect of note-taking on listening comprehension for lower-intermediate level EFL learners in China. Chinese Journal of Applied Linguistics, 35(4), 506-518.

Bui, D., \& Myerson, J. (2014). The role of working memory abilities in lecture note-taking. Learning and Individual Differences, 33, 12-22.

Bui, D., Myerson, J., \& Hale, S. (2013). Note-taking with computers: Exploring alternative strategies for improved recall. Journal of Educational Psychology, 105(2), 299-309.

Clerehan, R. (1995). Taking it down: Notetaking practices of L I and L2 students. English for Specific Purposes, 14(2), $137-155$.

Crawford, C. (1925). The correlation between college lecture notes and quiz papers. The Journal of Educational Research, 12 (4), 282-291.

Crawford, M. (2015). A study on note taking in EFL listening instruction. In P. Clements, A. Krause, \& H. Brown (Eds.), JALT 2014 Conference Proceedings (pp. 416-424). Tokyo, Japan: JALT.

Crawford, M. (2016). Lecture notetaking: Questions and answers. The Language Teacher, 40(2), 9-12.

Crawford, M., Ducker, N., MacGregor, L., Kojima, S., \& Siegel, J. (2016). Perspectives on note taking in EFL listening. In JALT Postconference Publication-JALT 2015. Tokyo, Japan: JALT. pp. 277-284.

Debopriyo, R., Brine, J., \& Murasawa, F. (2014). Usability of English notetaking applications in a foreign language learning context. Computer Assisted Language Learning, 29(1), 61-87.

Dearden, J. (2014). English as a medium of instruction: A growing global phenomenon. Oxford, UK: University of Oxford Press.

DiVesta, F., \& Gray, S. (1972). Listening and note taking. Journal of Educational Psychology, 63(1), 8-14.

Dunkel, P. (1988a). The content of L1 and L2 students' lecture notes and its relation to test performance. TESOL Quarterly, 22 (2), 259-278.

Dunkel, P. (1988b). Academic listening and lecture notetaking for Ll/L2 students: The need to investigate the utility of the axioms of good notetaking. TESL Canada Journal, 6(1), 11-26.

Dunkel, P., Mishra, S., \& Berliner, D. (1989). Effects of note taking, memory, and language proficiency on lecture learning for native and nonnative speakers of English. TESOL Quarterly, 23(3), 543-549. 
Flowerdew, J., \& Miller, L. (1997). The teaching of academic listening comprehension and the question of authenticity. English for Specific Purposes, 16(1), 27-46.

Hamp-Lyons, L. (1983). Survey of materials for teaching advanced listening and note-taking. TESOL Quarterly, 17(1), 109-122.

Hayati, A. M., \& Jalilifar, A. (2009). The impact of note-taking strategies on listening comprehension. English Language Teaching, 2(1), 101-111.

İpek, H. (2018). Perceptions of ELT students on their listening and note taking skills. International Online Journal of Education and Teaching (IOJET), 5(1), 206-217.

Jansen, R., Lakens, D., \& Ijsselsteijn, A. (2017). An integrative review of the cognitive costs and benefits of note-taking. Educational Research Review, 22, 223-233.

Kiewra, K., Benton, S., Kim, S., Risch, N., \& Christensen, M. (1995). Effects of note-taking format and study technique on recall and relational performance. Contemporary Educational Psychology, 20(2), 172-187.

Kobayashi, K. (2006). Combined effects of note-taking/reviewing on learning and the enchancement through interventions: A meta-analytic review. Educational Pscyhology, 26(3), 459-477.

Kusumoto, Y. (2019). EFL students' perceptions of note-taking and the effect of note-taking instruction. The Kyushu Academic Society of English Language Education Bulletin, 47, 47-56.

Larsen-Freeman, D. (2015). Research into practice: Grammar learning and teaching. Language Teaching, 48(2), 263-280.

Lim, P., \& Smalzer, W. (2014). Listening \& Notetaking Skills Level 2 (4th ed.). Boston, MA: National Geographic Learning and Heinle-Cengage Learning.

Lowen, S., \& Metzger, N. (2019). Motivating active note-taking in the classroom. Newsletter for Speech, Pronunciation, and Listening TESOL Interest Group. Retrieved from: http://newsmanager.commpartners.com/tesolsplis/issues/2019-03-05/3. html

Luo, L., Kiewra, K., Flanigan, A., \& Peteranetz, M. (2018). Laptop versus longhand note taking: Effects on lecture notes and achievement. Instructional Science, 46(6), 947-971.

Luo, L., Kiewra, K., \& Samuelson, L. (2016). Revising lecture notes: How revision, pauses, and partners affect note taking and achievement. Instructional Science, 44(1), 45-67.

McGrath, I. (2016). Materials evaluation and design for language teaching (2nd ed.). Edinburgh, UK: Edinburgh University Press.

Morehead, K., Dunlosky, J., \& Rawson, K. (2019). How much mightier is the pen than the keyboard for note-taking? A replication and extension of Mueller and Oppenheimer (2014). Educational Psychology Review, 31(3), 753-780.

Morehead, K., Dunlosky, J., Rawson, K., Blasiman, R., \& Hollis, R. (2019). Note-taking habits of 21st century college students: Implications for student learning, memory, and achievement. Memory, 27(6), 807-819.

Morell, T. (2018). Multimodal competence and effective interactive lecturing. System, 77, 70-79.

Mueller, P., \& Oppenheimer, M. (2014). The pen is mightier than the keyboard: Advantages of longhand over laptop note taking. Psychological Science, 25(6), 1159-1168.

Murata, K. (2018). Exploring EMI in higher education from an ELF perspective: Introduction. In K. Murata (Ed.), English medium instruction from an English as a lingua franca perspective (pp. 1-12). London, UK: Routledge.

Pauk, W., \& Owens, R. (2014). How to study in college (11th ed.). Boston, MA: Wadsworth Cengage Learning.

Piolat, A., Olive, T., \& Kellogg, R. (2005). Cognitive effort during note taking. Applied Cognitive Psychology, 19, $291-312$.

Reddington, L., Peverly, S., \& Block, C. (2015). An examination of some of the cognitive and motivation variables related to gender differences in lecture note-taking. Reading and Writing, 28, 1155-1185.

Sakurai, S. (2018). Promoting skills and strategies of lecture listening and note-taking in L2. Fukuoka University Journal of Humanities, 49(4), 1019-1046.

Sarosy, P., \& Sherak, K. (2013). Lecture Ready 2 (2nd ed.). Oxford, UK: Oxford University Press.

Sheldon, L. (1988). Evaluating ELT textbooks and materials. ELT Journal, 42(4), 237-246.

Siegel, J. (2016). A pedagogic cycle for EFL note-taking. ELT Journal, 70(3), 275-286.

Siegel, J. (2018a). Notetaking in ELT: Highlighting contrasts. TESOL Journal, 10(1), 1-5.

Siegel, J. (2018b). Teaching lecture notetaking with authentic materials. ELT Journal, 73(2), 124-133.

Siegel, J. (2018c). Did you take 'good' notes? On methods for evaluating student notetaking performance. Journal of English for Academic Purposes, 35, 85-92.

Siegel, J. (2019). Collaborative action research on notetaking: Simultaneous cycles. The European Journal of Applied Linguistics and TESOL, 8(2), 77-100.

Siegel, J. (2020a). Appreciating translanguaging in student notes. ELT Journal, 74(1), 86-88.

Siegel, J. (2020b). Effects of notetaking instruction on intermediate and advanced L2 English learners: A quasi-experimental study. Journal of English for Academic Purposes, 46. https://doi.org/10.1016/j.jeap.2020.100868

Siegel, J. (forthcoming). Developing notetaking in a second language: Insights from classroom research. London, UK: Routledge.

Siegel, J., Crawford, M., Ducker, N., Madarbakus-Ring, N., \& Lawson, A. (2020). Measuring the importance of information in student notes: An initial venture. Journal of English for Academic Purposes, 43, 1475-1585. 
Song, M. Y. (2012). Note-taking quality and performance on an L2 academic listening test. Language Testing, 29(1), 67-89. Teng, H. (2011). Exploring note-taking strategies of EFL listeners. Procedia Social and Behavorial Sciences, 15, 480-484.

Tsai, T., \& Wu, Y. (2010). Effects of note-taking instruction and note-taking languages on college EFL students' listening comprehension. New Horizons in Education, 58(1), 120-132.

Tomlinson, B. (2010). Principles of effective materials development. In N. Harwood (Ed.), English language teaching materials: Theory and practice (pp. 81-108). Cambridge, UK: Cambridge University Press.

Van de Meer, J. (2012). Students' note-taking challenges in the twenty-first century: Considerations for teachers and academic staff developers. Teaching in Higher Education, 17(1), 13-23.

Wammes, J., Meade, M., \& Fernandes, M. (2016). The drawing effect: Evidence from reliable and robust memory benefits in free recall. The Quarterly Journal of Experimental Psychology, 69(9), 1752-1776.

Joseph Siegel is associate professor (docent) in English at Stockholm University and Örebro University, Sweden, where he teaches TESOL methodology, linguistics, and applied linguistic research methods courses. He holds a Ph.D. in Applied Linguistics from Aston University. Among his research interests are L2 listening pedagogy, notetaking, pragmatics, and language teacher education.

Cite this article: Siegel, J. (2022). Research into practice: Teaching notetaking to L2 students. Language Teaching, 55(2), 245-259. https://doi.org/10.1017/S0261444820000476 